\title{
Participação de Alunas nos Cursos de Computação na Percepção de Alunos e Ex-alunos
}

\author{
Rafaela Brum ${ }^{1}$, Rosa Maria E. Moreira da Costa ${ }^{1}$, Aletéia Patrícia F. Araújo ${ }^{2}$, \\ Vera Maria B. Werneck ${ }^{1}$, Maria Clicia Steling de Castro ${ }^{1}$ \\ ${ }^{1}$ Universidade do Estado do Rio de \\ Janeiro - UERJ, \\ Programa de pós-graduação em \\ Ciências Computacionais \\ Rua São Francisco Xavier 524- 60 \\ andar - Bl. B, CEP 20550-013 \\ Rio de Janeiro - RJ - Brasil \\ ${ }^{2}$ Universidade de Brasília - UNB \\ Departamento de Ciência da \\ Computação \\ Campus da Unb, Sgan - Asa Norte, \\ CEP 70910-900 \\ Brasília, DF - Brasil \\ rafinhacbrum@gmail.com, rcosta@ime.uerj.br, aleteia@cic.unb.br, \\ vera@ime.uerj.br, clicia@ime.uerj.br
}

Resumo. Este artigo descreve o resultado de uma pesquisa realizada com alunos e ex-alunos de cursos de graduação da área tecnológica de diferentes universidades, que visou identificar percepções relacionadas à questão do baixo número de mulheres, principalmente, nos cursos ligados às áreas de computação e no mercado de trabalho desta área.

Abstract. This paper describes results of a research carried out with students and alumni of undergraduate courses from the technological area of different universities. It aimed to raise perceptions related to the issue of the low number of women in these courses, mainly in the courses related to the computing area and in the labor market.

\section{Introdução}

Estudos e discussões sobre o decréscimo do número de participantes femininas em cursos da área tecnológica têm sido realizados há alguns anos (Corneliussen, 2011; Abbate, 2012). No Brasil, na área da Computação, o declínio desse número é ressaltado em várias publicações recentes (SBC, 2014; Souza et al., 2017). Apesar do número de cursos na área (considerando Ciência da Computação, Engenharia da Computação, Sistemas de Informação, Licenciatura em Computação e mais recentemente, Engenharia de Software), apresentarem um crescimento expressivo entre 1998 e 2014 em todas as regiões do país, o número de matrículas de mulheres permanecem num mesmo patamar, não acompanhando o crescimento do número de matrículas de estudantes do gênero masculino (SBC, 2014). Se forem comparados os números de concluintes femininas em 2001 e em 2014, observa-se que em 2001 para cada dois concluintes masculinos havia uma concluinte feminina. Em 2014 essa relação foi de uma concluinte feminina para quatro masculinos. Essa queda passou a vigorar fortemente a partir do fim da década de 
80. Até então, havia um número significativo de participantes femininas nos cursos (SBC, 2014).

Várias iniciativas vêm sendo desenvolvidas em todo o mundo para despertar o interesse de estudantes femininas para a área tecnológica, como por exemplo, a criação de Conferências restritas para participantes femininas, com suporte de creches para crianças e foco em discussões técnicas (Abbate, 2012). No Brasil destaca-se o projeto Meninas Digitais da SBC, que acontece em diferentes estados do país (Sardiña e Maciel, 2016; Lauschner et al., 2016; Maciel e Bim, 2016).

Alguns trabalhos apresentam justificativas para que isso ocorra (Master et al., 2016; Santos, 2018). A justificativa vai da presença de estereótipos masculinos associados à superioridade de sua inteligência e que homens seriam mais bem sucedidos em carreiras das áreas de Exatas e as mulheres na área de Humanas. Outros pesquisadores discutem questões relacionadas aos jogos computacionais, que explorariam cenários com atividades violentas e que isso afastaria as meninas (Corneliussen, 2011).

Visando identificar a percepção dos estudantes sobre essa realidade, o objetivo deste artigo é apresentar e discutir o resultado de uma pesquisa realizada com alunos e ex-alunos de cursos da área tecnológica, com ênfase na área de Computação.

\section{Análise dos Resultados}

Para obter as respostas dos estudantes e dos formados foi construído um questionário em um formulário digital (Google Forms), com perguntas fechadas e abertas, que a princípio se restringiria ao Rio de Janeiro, mas que acabou se disseminando por outras regiões do país. Este instrumento online foi adotado por permitir um maior acesso aos participantes de diferentes universidades. Responderam ao questionário 89 pessoas, $60,7 \%$ do gênero feminino e $39,3 \%$ do gênero masculino, sendo classificados como alunos e ex-alunos de cursos da área tecnológica (Figura 1). As idades variam de 20 a 62 anos, com média de 28,8 anos.

A distribuição por estados é a seguinte: 6 participantes de SP, 9 de MG, 61 do RJ, 2 de $\mathrm{PE}, 1$ de SC, 9 do DF e 1 participante do Ceará. Em relação às universidades, 44 participantes masculinos e 26 participantes femininas são/foram de universidades públicas. Enquanto 12 participantes masculinos e 7 participantes femininas estudam ou estudaram em universidades particulares.

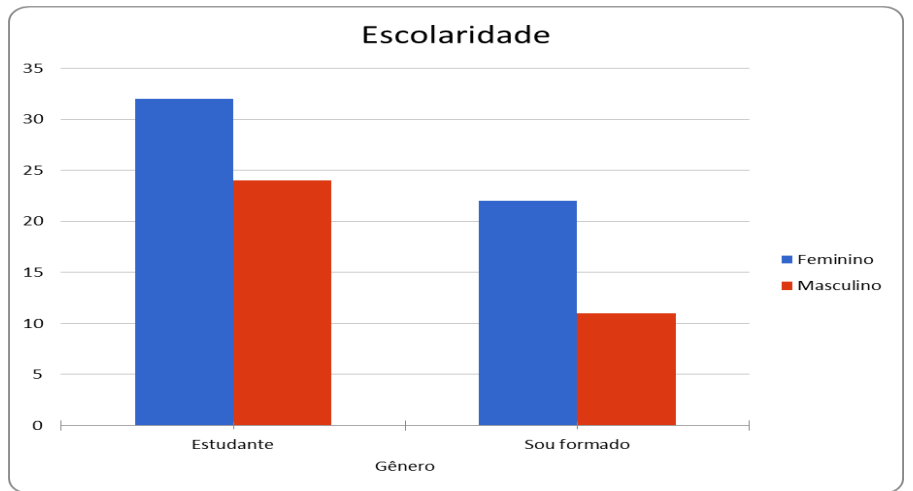

Figura 1. Gráfico do número de participantes classificados pelo nível de escolaridade. 
A Figura 2 apresenta o gráfico dos resultados das perguntas fechadas. Este mostra que $37,1 \%$ dos participantes responderam que sim e $62,9 \%$ que não percebiam diferenças no tratamento entre homens e mulheres no estágio/trabalho. Na parte aberta desta questão, as mulheres $(29,2 \%)$ ressaltaram que há mais desconfiança no resultado do trabalho feminino; que têm sua capacidade de trabalho subestimada porque não saberiam programar bem. Nesta questão, alguns homens disseram que há diferenças porque a mulher seria tratada com mais atenção e carinho.

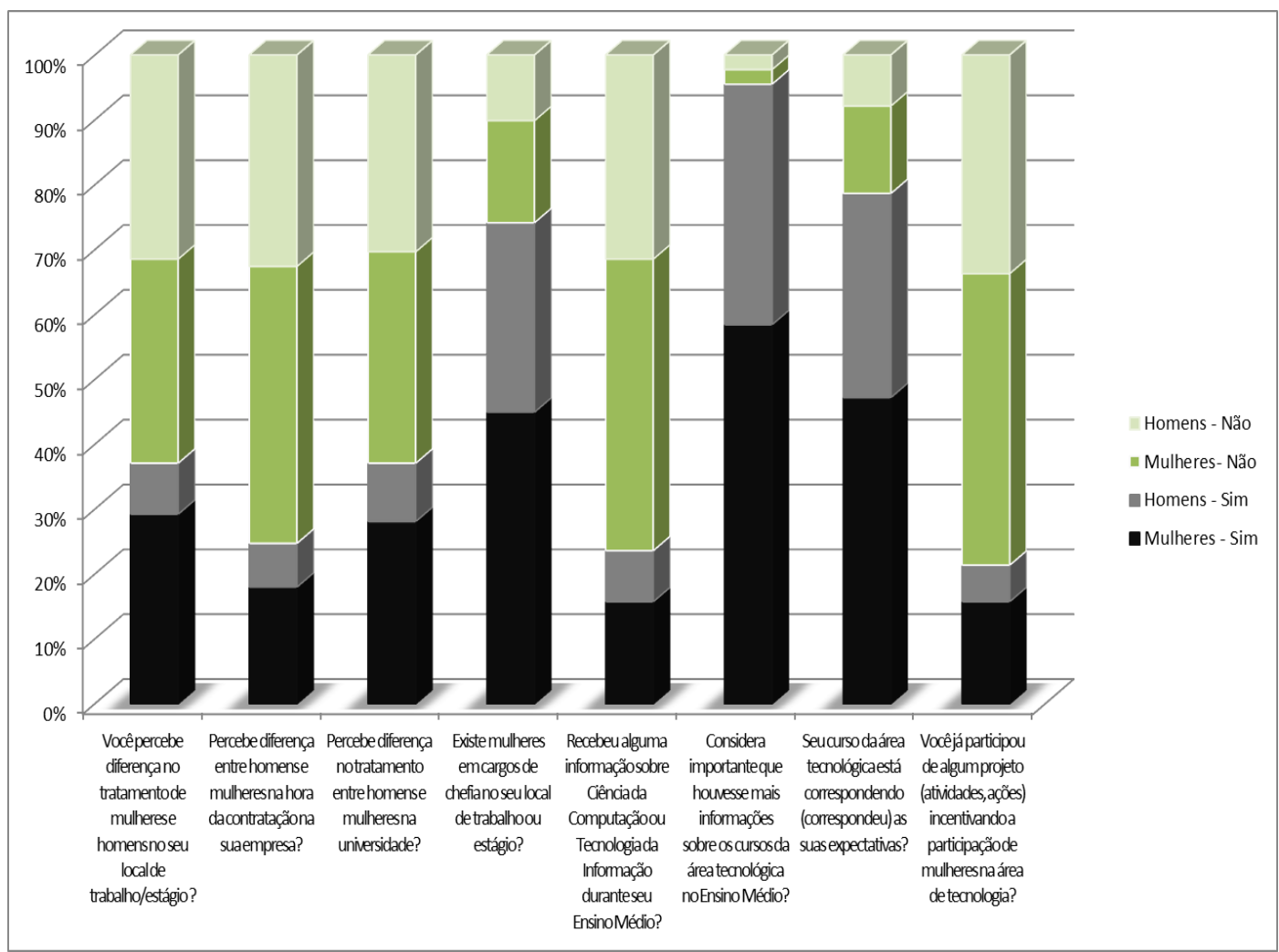

Figura 2. Gráfico dos resultados das perguntas fechadas

Diferentemente do que afirma Abbate (2012), que coloca que a entrada de homens e mulheres no mercado de trabalho da área de computação tem sido fortemente influenciada por desiguais oportunidades, na questão sobre contratação de profissionais, somente $24,7 \%$ dos participantes consideram que existe diferença entre homens e mulheres, sendo que $18 \%$ das mulheres percebem esse tratamento. Neste caso, a maioria $(75,3 \%)$ não vê diferença na contratação, sendo compatível com a resposta anterior.

Em relação ao tipo de tratamento na Universidade, $37,1 \%$ disseram que sentiam/sentiram diferenças de tratamento, enquanto $62,9 \%$ disseram que não. Ressaltamos que nas respostas abertas os participantes mencionaram que existiram comentários machistas por parte de professores e colegas e que ouviram comentários de professores dizendo que as mulheres são menos inteligentes, confirmando a difusão do estereótipo identificado por Wang et al. (2015) em uma pesquisa realizada com 1.739 jovens estudantes homens e mulheres nos Estados Unidos.

De acordo com os participantes $74,2 \%$ responderam que existem mulheres em cargos de chefia no estágio/trabalho e $25,8 \%$ que não. 
Uma questão importante foi sobre a obtenção de informações sobre Ciência da Computação e Tecnologia durante o Ensino Médio. Assim, 23,6\% dos participantes responderam ter recebido essa informação e a grande maioria $(74,2 \%)$ não recebeu. Neste caso, a grande maioria dos que responderam sim (81\%), cursaram Cursos Técnicos na área tecnológica. Contrariamente ao que verificou Wang et al. (2015), que identificou uma significativa influência dos pais na escolha das carreiras dos filhos, somente um participante apontou ter recebido informações relevantes do pai, que é profissional de Tecnologia da Informação.

Perguntados se eles já haviam participado de atividades de integração das mulheres em atividades associadas à área tecnológica, 21,3\% disseram que sim e 78,7\% que não. Dos que disseram sim, foram citados os projetos Include Meninas, Meninas Digitais, Rails Girls e PyLadies. Uma das participantes citou que é embaixadora do Technovation Challenge, que busca incentivar meninas de 10 a 18 anos a participarem de atividades ligadas à Computação.

Uma pergunta aberta questionou sobre a percepção dos participantes relacionada à diminuição do número de mulheres nos cursos das áreas tecnológicas, em especial da Computação. Algumas das respostas apontaram que isso acontece porque as mulheres têm dificuldades no raciocínio lógico, já que têm um predomínio de raciocínio mais emocional; que há falta de incentivo; que o ambiente dos cursos é hostil a elas; que há baixa valorização da profíssão e falta de incentivo por parte das políticas públicas.

\section{Comentários Finais}

Apesar de esta pesquisa ter sido realizada com um número considerado estatisticamente baixo, apresentou resultados similares às pesquisas realizadas em outros países e discutidas por Hill et al. (2010) e Wang et al. (2015).

O quadro de decréscimo do número de mulheres nos cursos das áreas computacionais no Brasil, segundo apresentado em 2014 pela SBC (2014), está alinhado com o quadro apresentado por Hill et al. (2010), que mostra um decréscimo acentuado no número de mulheres estudantes e formadas a partir dos anos 80 nestas área. E, segundo esses autores, nos Estados Unidos, isso não aconteceu com outras carreiras, tais como Matemática, Biologia, Engenharia, Química e Física e que ao contrário, tiveram um aumento no número de participantes femininas.

Logo, é preciso que mais iniciativas apresentem outra visão das carreiras das áreas computacionais, desmistificando padrões de comportamento preconceituoso da sociedade, onde as meninas são consideradas inferiores aos meninos. Como observado nesta pesquisa, algumas estudantes participaram de iniciativas deste tipo e estão cursando carreiras de computação. Mas, é preciso intensificar o alcance destes projetos, para ampliar o contato das meninas com as tecnologias o mais cedo possível. De acordo com Wang et al. (2015) com muita frequência, as mulheres têm como meta na carreira "ajudar outras pessoas" e que elas não veem possibilidade disso nas carreiras tecnológicas. Então, é preciso que os projetos de integração de meninas nas áreas de tecnologia ressaltem as possibilidades oferecidas principalmente, pela computação, no apoio ao tratamento de diversos distúrbios e síndromes por meio, por exemplo, de Serious Games; no apoio a diferentes tipos de deficiências físicas e intelectuais; no suporte a pesquisas que impulsionam o crescimento econômico e social do homem do 
campo, dentre outros, ressaltando o retorno social que as novas tecnologias podem aportar para várias camadas da sociedade.

Por outro lado, é preciso ainda que os meios de comunicação ampliem a divulgação de casos de mulheres bem sucedidas em cargos da área tecnológica e que as universidades tenham programas de incentivo específicos para evitar o abandono dos cursos por parte das alunas.

\section{Referências}

Abbate, J. (2012). Recoding gender: Women's changing participation in computing. MIT Press.

Corneliussen, H. (2011). Gender-technology relations: exploring stability and change. Springer.

Hill, C., Corbett, C., \& St Rose, A. (2010). Why So Few? Women in Science, Technology, Engineering, and Mathematics. Washington, DC: American Association of University Women. Disponível em: http://files.eric.ed.gov/fulltext/ED509653.pdf. Acessado em abril 2018.

Lauschner, T., De Freitas, R., Nakamura, F. \& Gomes, L. L. (2016). "Cunhantã digital: programa de incentivo a participação de mulheres da região amazônica na computação e áreas afins." In $10^{\circ}$ Women in Information Technology (WIT 2016), Porto Alegre. In: Anais do XXXVI Congresso da Sociedade Brasileira de Computação (CSBC 2016).

Maciel, C., \& Bim, S. A. (2017). "Programa Meninas Digitais-ações para divulgar a Computação para meninas do ensino médio." In: Anais do Computer on the Beach, 327-336.

Master, A., Cheryan, S., \& Meltzoff, A. N. (2016). "Computing whether she belongs: Stereotypes undermine girls' interest and sense of belonging in computer science". In: Journal of Educational Psychology, 108(3), 424.

Santos, C.M., (2018). "Por que as mulheres "desapareceram" dos cursos de computação?" In: Jornal da USP, Disponível em http://jornal.usp.br/universidade/por-que-as-mulheresdesapareceram-dos-cursos-de-computacao, publicado em: 7 de março de 2018.

Sardiña I.M., Maciel, C. (2016). "Ações para Incentivar Meninas do Ensino Médio a Cursar Carreiras Tecnológicas da Universidade Federal do Rio Grande do Norte". In: $10^{\circ}$ Women in Information Technology (WIT 2016), Porto Alegre. In: Anais do XXXVI Congresso da Sociedade Brasileira de Computação (CSBC 2016).

SBC - Educação Superior em Computação - Estatísticas - 2014. Disponível em: http://www.sbc.org.br/documentos-da-sbc/summary/133-estatisticas/1007-estatisticasdaeducacao-superior-2014. Acessado em março de 2018.

Souza, N.N. M., Lima, A.C.G., Sousa, D.F., (2017). "Análise da Participação Feminina nos Cursos de Licenciatura em Computação e Sistemas de Informação". In $11^{\circ}$ Women in Information Technology (WIT 2017). In: Anais do XXXVI Congresso da Sociedade Brasileira de Computação (CSBC 2017).

Wang, J., Hong, H., Ravitz, J., \& Ivory, M., (2015). "Gender differences in factors influencing pursuit of computer science and related fields". In: Proceedings of the 2015 ACM Conference on Innovation and Technology in Computer Science Education, 117-122. 